SCIREA Journal of Medicine

http://www.scirea.org/journal/PM

February 10, 2022

Volume 6, Issue 1, February 2022

https://doi.org/10.54647/pm31150

\title{
IMPACT OF COVID-19 ON BMI OF UNIVERSITY STUDENTS IN PAKISTAN
}

\author{
Hira Fatima 1, Sana Ataullah ${ }^{1}$, Fatimah K. Rasool 2, Ahmed K. Rasool ${ }^{\text {, }}$, Farhat Bashir ${ }^{4}$ \\ ${ }^{1}$ Final year medical student, united medical and dental college, Pakistan \\ 2 3rd year student, sindh medical college, Pakistan \\ ${ }^{3} 1$ st year medical student, dow medical college, Pakistan \\ ${ }^{4}$ Professor, department of medicine, united medical \& dental college, Pakistan
}

\begin{abstract}
COVID-19 has created a new normal for the world. The social restrictions that are linked to the epidemic control measures have negatively impacted the daily routine of the population. Obesity is major contributor to the rise of non-communicable diseases in South Asia and Middle-East. A trend of increasing obesity had already been noticed in the Pakistani youth. We need to ascertain the effect of COVID-19 on the BMI (body mass index) of our youth so that the adverse effects may be countered.
\end{abstract}

Objective: This study was conducted to determine the impact of COVID-19 on the BMI of university students in Pakistan.

Subjects \& Methods: A cross-sectional multi-center study was conducted through an online questionnaire among the university students of Pakistan. The BMI before and 6 months after the COVID-19 lockdown was assessed. The changes in caloric intake and physical activity were also assessed. Paired student's t-test, Chi-square test and McNemar tests were used to 
assess the association between different variables. P-value of $<0.05$ was considered statistically significant.

Results: The larger proportion of the study population was female [ $\mathrm{n}=230(68.5 \%)]$, had normal weight [ $41 \%$ before and 39\% during COVID] and lived in urban areas. The ages ranged from 18 to 35 years $(21.4 \pm 2.1$ mean $\pm \mathrm{SD})$. Around $30.7 \%$ of the population was overweight and $16.7 \%$ was obese before the epidemic, while 6 months after the epidemic $29.5 \%$ and $18.2 \%$ of the students were overweight and obese respectively. There was no significant change of BMI among the study population. There was no significant change in the dietary habits and physical activity among the students before and 6 months after the epidemic.

Conclusion: There was no impact of the COVID-19 epidemic on the BMI of university students in Pakistan. A very high percentage of students were either overweight or obese. There is urgent need for inclusion of health education in the educational system in Pakistan to deal with the emerging cardio-metabolic disease epidemic.

Keywords: COVID-19, BMI, university students.

\section{Introduction:}

Preventive medicine is the most important aspect to consider when public health policy planning is undertaken. But this is an under-served part of health delivery system in Pakistan. We can develop such programs based on epidemiological surveys and identification of populations in need of health education and awareness. The youth, at the brink of joining professional life are a country's major asset and any health problems identified and resolved at this stage would benefit the professionals of future years.

Cardio-metabolic diseases are on the rise worldwide, and nowhere is it more evident than in the Middle-East and South Asia. This is attributable to changing lifestyles. With improvement of the caloric value of diet and reduction in physical activity we are observing a very real obesity epidemic in Pakistan. ${ }^{1}$ While it is a recognized risk factor for cardio-metabolic diseases, obesity is also associated with certain types of cancer, gall bladder disease, osteoarthritis, gout and certain pulmonary diseases ${ }^{2}$. Obesity in young age leads to obesity in adult life. We have observed a rising incidence of obesity among adolescents. Being 
underweight also poses serious problems, especially in a developing country like Pakistan. A report on the nutritional status of Pakistanis reported a high prevalence of the population as underweight, majority being women of reproductive age. ${ }^{3}$ Being underweight affects both sexes but the implications in the females are far-reaching with anemia, infertility or complications in pregnancy endangering both the life of the mother and their babies ${ }^{4}$.

The pandemic of the coronavirus SARS-CoV-2 (COVID-19), with the lock-downs associated with it, has caused significant disruption in the lifestyle of every individual. It has created a new normal in the society which has led to an even more restricted lifestyle. After the first case was confirmed in Pakistan, the country was placed under lockdown in the end of February 2020. The lockdown was extended twice and was finally eased sequentially from May 2020. The educational institutions were opened from middle of September 2020, only to be closed again after the emergence of the second wave of COVID-19. Our youth were confined to their homes for more than six months. With the third and even fourth waves emerging in subsequent months and educational institutions offering online education, the patterns of living for the students has remained disrupted. The protective measures advised by the health advisory, has placed emphasis on social distancing even after resumption of economic and educational activities. Due to the risk of accelerated spread of infection most areas of Pakistan and rest of the world, have faced different grades of social restriction since March 2020.5 Especially those activities which were not considered essential, including schools/university, sport activities, shops, and factories were shut down. ${ }^{6}$ Students especially had to stay at home and after a short interval online teaching was introduced. This enforced quarantine can have a heavy physical and psychological impact. ${ }^{7}$ Usual lifestyle habits have been heavily disrupted by the mandatory stay-at-home orders, which may result in important behavior changes, particularly dietary habits and exercise, in this kind of natural experiment, "forced" by an unpredictable emergency. ${ }^{8}$ The rise in unstructured time might induce overeating and increased screen time which is contributed to by the online teaching. Furthermore, social isolation might worsen lifestyle behaviors with enhanced sedentarism, as well as decreased outdoor time and increased weight gain. ${ }^{9}$

The objective of this research was to ascertain the change in BMI of university students during the COVID-19 pandemic and to assess the factors contributing to it. 


\section{Subjects \& Methods:}

A multi-center cross-sectional study was planned in undergraduate students from various universities in Pakistan. It was conducted through an online questionnaire during the months of August to September. The research team generated the questionnaire based on review of literature and feedbacks obtained in research group meetings. The questions were grouped and prioritized. After conducting a pilot study the questions which seemed unclear were changed and an online questionnaire was finalized. The questionnaire included the demographic data, physical variables which allowed the researchers to calculate the BMI (both pre and postCOVID-19); and the factors affecting the BMI. The subjects were both public and private university students in Pakistan who were impacted by the lockdown due to COVID-19. All university students aged 18 to 35 were included in the study. They were recruited through convenience sampling via email, text messages and social media. Students having chronic illness or eating disorders were excluded. Students unable to completely fill the questionnaire were also excluded. Around 450 students were asked to fill the questionnaire. Incomplete questionnaires were discarded. The study protocol was approved by the Institutional Review Board. Each subject gave informed consent before filling the proforma.

The weight (in kilograms) and height (in centimeters) of the participants was reported by the participants. BMI was calculated from height and weight measurements and then categorized into underweight, normal weight, overweight and obese (BMI $<19 \mathrm{~kg} / \mathrm{m}^{2}$ as underweight, 19.1 to $22.9 \mathrm{~kg} / \mathrm{m}^{2}$ as normal BMI, 23 to 25 as overweight and $>29$ as obese). ${ }^{10}$ Participant demographics namely age, gender and place of permanent residence were considered as the other independent variables. The dietary habits, physical activity and other lifestyle factors were also recorded by the participants and labeled as independent variables.

The data was entered and analyzed on SPSS 23.0. The continuous variables were computed with mean and standard deviation, while the categorical variables were computed with numbers and percentages. The association between the variables and change in BMI was assessed through paired Student's t-test, Chi square test and McNemar test according to type of varisble. P-value of $<0.05$ was considered significant 


\section{Results:}

Among a total of 387 students $106(31.5 \%)$ were male and $230(68.5 \%)$ were female. The ages ranged from 18 to 35 years $(21.4 \pm 2.1$ mean $\pm \mathrm{SD})$. The mean BMI of the study population before COVID-19 pandemic was $23.47 \pm 5.05 \mathrm{~kg} / \mathrm{m}^{2}$ and after the lockdown 6 months after start of pandemic was $23.41 \pm 4.99 \mathrm{~kg} / \mathrm{m}^{2}$. The difference between the BMI was not significant. In male subjects the mean pre-COVID BMI was $22.65 \pm 4.42 \mathrm{~kg} / \mathrm{m}^{2}$ while in females is 25.07 $\pm 5.74 \mathrm{~kg} / \mathrm{m}^{2}$, while BMI during COVID-19 was $22.60 \pm 4.43 \mathrm{~kg} / \mathrm{m}^{2}$ in males and $25.37 \pm 5.77 \mathrm{~kg} / \mathrm{m}^{2}$ in females. The is significant difference in BMI of female and male students both before and during COVID-19 (p-value $<0.05$ ). When considering categorization of BMI into under-weight, normal, overweight and obese students, there was no significant change among the groups but the percentage of obese students increased from 16.7 to 18.2 during COVID, while more students became under-weight during COVID. (Table-1)

Table 1: WEIGHT \& BMI OF SUBJECTS (before \& during COVID-19)

\begin{tabular}{|c|c|c|c|c|}
\hline \multicolumn{2}{|c|}{ VARIABLES } & $\begin{array}{c}\text { BEFORE } \\
\text { COVID-19 }\end{array}$ & $\begin{array}{c}\text { DURING } \\
\text { COVID-19 }\end{array}$ & p-value \\
\hline \multicolumn{2}{|c|}{ WEIGHT(kg) $($ mean \pm SD $)$} & $62.1 \pm 15$ & $62.3 \pm 15$ & $0.5^{\#}$ \\
\hline \multicolumn{2}{|c|}{$\mathbf{B M I}\left(\mathbf{k g} / \mathbf{c m}^{2}\right)($ mean $\pm \mathrm{SD})$} & $23.41 \pm 4.99$ & $23.47 \pm 5.05$ & $0.46^{\#}$ \\
\hline \multicolumn{2}{|c|}{ BMI in male subjects $\left(\mathbf{k g} / \mathbf{c m}^{2}\right)($ mean \pm SD $)$} & $22.65 \pm 4.42$ & $22.60 \pm 4.43$ & $\mathbf{0 . 5 9} 9^{\#}$ \\
\hline \multicolumn{2}{|c|}{ BMI in female subjects $\left(\mathbf{k g} / \mathbf{c m}^{2}\right)($ mean $\pm S D)$} & $25.07 \pm 5.74$ & $25.37 \pm 5.77$ & $\mathbf{0 . 0 3}^{\#}$ \\
\hline \multirow{4}{*}{$\begin{array}{c}\text { CATEGORY } \\
\text { ACCORDING TO BMI } \\
\text { (all population) } \\
\{\text { number(percentage })\}\end{array}$} & Underweight & $39(11.6 \%)$ & $44(13.1 \%)$ & \multirow{4}{*}{$0.35 *$} \\
\hline & Normal weight & $138(41.1 \%)$ & $132(39.3 \%)$ & \\
\hline & Overweight & $67(19.9 \%)$ & $58(17.3 \%)$ & \\
\hline & Obese & $92(27.4 \%)$ & $102(30.4 \%)$ & \\
\hline \multirow{4}{*}{$\begin{array}{c}\text { CATEGORY } \\
\text { ACCORDING TO BMI } \\
\text { (In female subjects) }\end{array}$} & Underweight & $33(14.3 \%)$ & $38(16.5 \%)$ & \multirow{4}{*}{$0.80 *$} \\
\hline & Normal weight & $103(44.8 \%)$ & $96(41.7 \%)$ & \\
\hline & Overweight & $38(16.5 \%)$ & $37(16.1 \%)$ & \\
\hline & Obese & $56(24.3 \%)$ & $59(25.7 \%)$ & \\
\hline \multirow{4}{*}{$\begin{array}{c}\text { CATEGORY } \\
\text { ACCORDING TO BMI } \\
\text { (In male subjects) }\end{array}$} & Underweight & $6(5.7 \%)$ & $6(5.7 \%)$ & \multirow{4}{*}{$0.10 *$} \\
\hline & Normal weight & $35(33 \%)$ & $36(34 \%)$ & \\
\hline & Overweight & $29(27.4 \%)$ & 21(19.8\%) & \\
\hline & Obese & $36(34 \%)$ & $43(40.6 \%)$ & \\
\hline
\end{tabular}


Before the pandemic $27 \%$ of males were overweight and $13.5 \%$ were obese respectively and there was no significant difference after 6 months of pandemic. $37.7 \%$ of females were overweight and $23.6 \%$ were obese pre-COVID and during the pandemic $33 \%$ were overweight and $27.4 \%$ became obese. (Table-1)

Around $36 \%$ of the population gained weight, $42.6 \%$ lost weight while $21.4 \%$ had no change in BMI.

The lifestyle including physical activity and dietary habits among the subjects was analyzed according to categorization by reduction of BMI, no change and increase in BMI during COVID-19.

Students who lost weight during COVID-19 significantly reduced exercise and increased snacking while there was no significant change in intake of fast food and soda or energy drinks. (Table-2)

TABLE 2: EFFECT OF DIFFERENT LIFESTYLE FACTORS ON REDUCTION OF BMI

\begin{tabular}{|c|c|c|c|c|}
\hline \multicolumn{2}{|c|}{ VARIABLE } & $\begin{array}{c}\text { BEFORE COVID- } \\
19\end{array}$ & $\begin{array}{c}\text { DURING COVID- } \\
19\end{array}$ & P-VALUE \\
\hline \multirow{3}{*}{ EXERCISE } & YES & 52 & 57 & \multirow{2}{*}{0.59} \\
\cline { 2 - 5 } & NO & 69 & 64 & \multirow{2}{*}{0.01} \\
\hline $\begin{array}{c}\text { NUMBER OF SNACKS PER } \\
\text { DAY }\end{array}$ & NONE & 75 & 102 & \multirow{2}{*}{0.00} \\
\cline { 2 - 5 } FAST FOOD PER WEEK & $1-2$ & 46 & 19 & \multirow{2}{*}{0.00} \\
\cline { 2 - 5 } & $0-1$ & 54 & 32 & 56 \\
\hline SODA PER DAY & NONE & 35 & 65 & \\
\cline { 2 - 5 } & $1-3$ & 86 & 67 & \\
\hline
\end{tabular}


Among students who maintained weight during the epidemic there was no significant change of exercise or soda intake, with significant reduction in fast food intake but snacking was increased. (Table-3)

TABLE 3: EFFECT OF DIFFERENT LIFESTYLE FACTORS ON MAINTAINED BMI

\begin{tabular}{|c|c|c|c|c|}
\hline \multicolumn{2}{|l|}{ VARIABLE } & $\begin{array}{l}\text { BEFORE COVID- } \\
19\end{array}$ & $\begin{array}{c}\text { DURING } \\
\text { COVID-19 }\end{array}$ & P-VALUE \\
\hline \multirow{2}{*}{ EXERCISE } & YES & 29 & 33 & \multirow{2}{*}{0.52} \\
\hline & NO & 43 & 39 & \\
\hline \multirow{2}{*}{$\begin{array}{c}\text { NUMBER OF SNACKS PER } \\
\text { DAY }\end{array}$} & NONE & 62 & 51 & \multirow{2}{*}{0.01} \\
\hline & $1-2$ & 10 & 21 & \\
\hline \multirow{2}{*}{ FAST FOOD PER WEEK } & $0-1$ & 44 & 57 & \multirow{2}{*}{0.004} \\
\hline & $2-4$ & 28 & 15 & \\
\hline \multirow{2}{*}{ SODA PER DAY } & NONE & 28 & 27 & \multirow{2}{*}{1.00} \\
\hline & $1-3$ & 44 & 45 & \\
\hline
\end{tabular}

Students' whose BMI increased during this time showed that there was non-significant reduction of exercise and significant reduction of intake of fast food, soda and snacks. (Table4)

TABLE 4: EFFECT OF DIFFERENT FACTORS ON INCREASED OF BMI

\begin{tabular}{|c|c|c|c|c|}
\hline \multicolumn{2}{|l|}{ VARIABLE } & $\begin{array}{l}\text { BEFORE COVID- } \\
19 \\
\end{array}$ & $\begin{array}{l}\text { DURING COVID- } \\
19 \\
\end{array}$ & P-VALUE \\
\hline \multirow{2}{*}{ EXERCISE } & YES & 63 & 38 & \multirow{2}{*}{0.001} \\
\hline & NO & 80 & 105 & \\
\hline \multirow{2}{*}{$\begin{array}{c}\text { NUMBER OF SNACKS PER } \\
\text { DAY }\end{array}$} & NONE & 112 & 79 & \multirow{2}{*}{0.001} \\
\hline & $1-2$ & 31 & 64 & \\
\hline \multirow{2}{*}{ FAST FOOD PER WEEK } & $0-1$ & 80 & 81 & \multirow{2}{*}{1.00} \\
\hline & $2-4$ & 63 & 62 & \\
\hline \multirow{2}{*}{ SODA PER DAY } & NONE & 54 & 46 & \multirow{2}{*}{0.16} \\
\hline & $1-3$ & 89 & 97 & \\
\hline
\end{tabular}




\section{Discussion:}

Obesity, globally measured as BMI, is not gender specific and is significantly correlated with total body fat. It is a modifiable risk factors contributing to the top two causes of global mortality. ${ }^{11}$ The incidence of obesity has increased rapidly during recent decades. And according to the World Health Organization (WHO), it has more than doubled since 1980 and is expected to rise further. ${ }^{12}$ It is a public health and policy problem because of its magnitude and health effects. ${ }^{13}$ Obesity also is a factor in the pathogenesis of hypertension, diabetes mellitus, nonalcoholic fatty liver disease, metabolic syndrome and some malignancies among other disorders.

Asian populations have different associations between BMI, percentage of body fat, and health risks than do European populations. Obesity in south Asians has different reference levels as compared to Caucasian populations, normal BMI being 18 to $22.9 \mathrm{~kg} / \mathrm{m}^{2} .{ }^{10}, 14$

We have assessed the change in BMI during the COVID-19 pandemic among university students and assessed the association with dietary habits and physical activity.

When we consider the prevalence of obesity and over-weight in our study population, it is comparable to other studies involving students in South Asia and MENA (Middle East \& North Africa) region. In a study conducted in Saudi Arabia 23.6\% women and 14\% men were obese, while $30.7 \%$ for men and $28.4 \%$ of females were overweight. This study was conducted in the community ${ }^{15}$ Another study involving college students in the same country showed that $21.8 \%$ of the students were overweight and $15.7 \%$ were obese. ${ }^{16} \mathrm{~A}$ local research revealed $27 \%$ overweight, $7 \%$ obese and $60 \%$ students had normal weight. This percentage was with an over-weight BMI of more than $25 \mathrm{~kg} / \mathrm{m}^{2}$, while in our study the BMI cut-off for overweight was $22.9 \mathrm{~kg} / \mathrm{m}^{2}$. Another study showed obesity of $3 \%$ and $13 \%$ among public and private sector medical college students in Karachi, Pakistan. Obesity was lower in Indian students with obesity around $2 \%$ to $3 \%$. Different student populations from the developing countries showed $12-27 \%$ overweight populations. Obesity was found to be higher in MiddleEastern students as compared to students from Africa and the sub-continent. ${ }^{17}$

We know that lower literacy status is associated with lesser health knowledge. But having such a high prevalence of obesity in college students highlights the need to focus more on health education. 
This increasing trend of weight gain especially among the MENA region is mainly because of changing lifestyle. Improvement of economic status and dispensible income in the population has led to use of a high calorific value of diet. Changing dietary options with a higher consumption of fast food and soft drinks (western diets), less physical activity has contributed to the increase in the over-weight population in this region.

COVID-19 showed no significant change in mean BMI among our study population. But we observed that underweight subjects lost weight while overweight and obese subjects gained weight as was seen in a European study. ${ }^{18}$ Another European study also demonstrated weight gain in obese subjects during COVID-19 lockdown. ${ }^{19}$ We know that obese patients have poorer outcome to COVID-19. ${ }^{20}$

In a systemic review conducted for evaluation of factors leading to obesity among students showed that younger age, good economic status, high income country, poor dietary habits and lack of physical activity, smoking, childhood abuse and depression are factors contributing towards obesity in male students. In female students older age, depression, high income country, childhood abuse and unhealthy dietary habits lead to obesity. ${ }^{17}$

Our study showed that the lockdown affected the overweight/obese population more than the students with normal BMI. But there was no consistent pattern of changes in their eating pattern. A Polish study has shown that the obese population consumed less fruit, vegetables and legumes and more fast-food, meat and dairy-products during lockdown. ${ }^{18}$

COVID-19 has emphasized that our youth are already facing unhealthy lifestyle choices regarding their diet and physical activity and the epidemic has led to even more restrictions on exercise. Inaccessibility of gyms, closure of parks and discontinuation of sporting events along with prolonged periods of sedentary behavior due to online learning will lead to further deterioration of lifestyle. Adding to this the stress of the epidemic with its accompanying uncertainty leading to an increase in anxiety and depression will contribute to the eating disorders and inactivity. This psychological stress was aggravated by the lockdowns causing public panic and misinformation, doom-saying, fake news and imprecise science all contributed to the anxiety.

Food is a strategy to cope with stress and although the eating out at restaurants was not possible but take-out was available and this can contribute to perpetuation of unhealthy eating habits. 
Health education should concentrate on both communicable and non-communicable diseases. A comprehensive health education plan will inform our population about healthy eating choices and behaviors. It will stress on physical activity as a preventive health measure.

Lack of exercise was found to account for $6-10 \%$ of causation to most non-communicable diseases and around $9 \%$ of causation to mortality caused by these diseases. ${ }^{21}$ The subjects in our study population were not exercising adequately. We need to educate our youth about the importance of physical activity. This will not only optimize their BMI but will also improve their overall health and reduce healthcare costs. ${ }^{22}$ Not only is there no personal motivation to exercise, but we also do not have a culture of exercise for the purpose of health maintenance. The universities should ensure socially acceptable places to exercise for both male and female students. There should be designated time available to the students for exercising. Encouragement of physical activity can be in form of sports tournaments and competitions.

The students who gained weight exercised less as compared to their pre-COVID routine. This was the only factor which negatively impacted the BMI as they did reduce snacking significantly. This shows that exercise has a lot of impact on BMI. We did not assess the duration or type of exercise in our subjects but it is recommended that education about the advantages of exercise and provision of facilities for physical activities should be provided to our youth. Lack of health education and use of technology both for education and entertainment has reduced the level of physical activity among the students. Lack of exercise in University students can be caused by lack of discipline, poor time management, lack of knowledge, and lack of definite organized exercise regimens in their daily schedules. ${ }^{23}$

A US study has shown that people who exercised were found to have a $40 \%$ lower risk of all cause mortality in comparison to non-exercising individuals. ${ }^{22}$

It is important to assess any changes in weight and BMI in our university students so that we can focus on developing strategies to educate them about adoption of healthy lifestyle. Improvement of lifestyle of this portion of the society will have long standing effects whose trickle down effect may be observed throughout the society.

It has been observed in various studies that weight gain is the norm seen in lockdown. This was due the variation in eating habits. Weight gain was observed in the majority of the subjects in an Irish study during COVID-19. This was due to altered dietary habits. Stress, having the household all living at home contributed to this change. This is a European observation and the results cannot be completely extrapolated on our population but 
investigating the factors contributing to weight gain in the epidemic can provide insight regarding similar factor in our population. It was also found that vulnerable groups were affected by lack of food security during the lockdown.

We did assess smoking and addiction among the study subjects but as most subjects were female and very few smoked or had an addiction we were not able to analyze the effect of smoking and/or addiction on BMI. We also questioned the students about screen time but as screen time increased a lot for every student due to online teaching the role of screen time on BMI was not assessed.

The youth are responding to this pandemic in different ways. Many psychological factors are related to stress, social isolation and media coverage of the situation. Research regarding psychological stress during COVID-19 has reported poor sleep quality, anxiety, depression, and post traumatic stress disorder in the studied populations internationally. ${ }^{24,25,26}$ Not only are the physical factors i.e dietary changes, loss of opportunity for physical activity and enforced sitting for on-line classes leading to changes in BMI but also the stress and anxiety caused by this epidemic will lead to different coping behaviours that can have an effect on BMI. Stress can lead to both eating more, eating less or binge-eating. The stress seems to have perpetuated the same behaviours that placed a person in a certain BMI category. Underweight students lost weight while over-weight and obese students gained it. It is a concern antecedent issues were aggravated in the subjects.

There have been some positive aspects of this time i.e spending more time with family, development of a sense of social responsibility and acknowledgement of need for reliable information. $^{27}$

It is to be hoped that the students will learn the importance of preventive measures on both communicable and non-communicable diseases. It is critical that the students are educated about preventive health.

\section{Conclusion:}

There was no impact of the COVID-19 epidemic on the BMI of university students in Pakistan. There is urgent need for inclusion of preventive health education in the educational system in Pakistan to deal with the emerging cardio-metabolic disease epidemic. 


\section{References:}

[1] Bhanji S, Khuwaja AK, Siddiqui F, Azam I, Kazmi K. Underestimation of weight and its associated factors among overweight and obese adults in Pakistan: a cross sectional study. BMC Public Health. 2011;11(1):363.

[2] WHO consultation. World Health Organ Tech Rep Ser 2000, 894:i-xii,:1-253.

[3] Qureshi SK, Nazli H, Soomro GY. Nutritional Status of Pakistan. Institute of Nutritional Economics (Islamabad, Pakistan). 2001; Report No.: 8. Available at URL: http://www.pide.org.pk/Mimap/Report08.pdf.

[4] Resse MATB. Underweight: a heavy concern. Today's Dietitian. 2008; 10(1):56.

[5] Maestra SL, Abbondandolo A, Flora SD. Epidemiological trends of COVID-19 epidemic in Italy during March 2020. From 1,000 to 100,000 cases. J. Med. Virol. 2020. Mar 20; doi: 10.1002/jmv.25908.

[6] Gatto M, Bertuzzo E, Mari L, Miccoli S, Carraro L, Casagrandia R, Rinaldo A. Spread and dynamics of the COVID-19 epidemic in Italy: Effects of emergency containment measures. Proc. Natl. Acad. Sci. USA 2020, 202004971.

[7] Ryan DH, Ravussin E, Heymsfield S. COVID 19 and the patient with obesity-The editors speak out. Obesity 2020; $28: 847$.

[8] Thomson, B. The COVID-19 pandemic: A global natural experiment. Circulation 2020;142:14-16

[9] Balanzá-Martínez V, Atienza-Carbonell B, Kapczinski F, Boni RBD. Lifestyle behaviours during the COVID-19-Time to connect. Acta Psychiatr. Scand. 2020 May; 141(5): 399-400.

[10] WHO. Appropriate body-mass index for Asian populations and its implications for policy and intervention strategies [Internet] Available from: https://www.who.int/nutrition/publications/ bmi__Depa asia_strategies.pdf [Cited December 2020].

[11] WHO Top 10 causes of death 2018. http://www.who.int/mediacentre/factsheets/fs310/en /. Accessed 20/01/2020.

[12] Finucane MM, Stevens GA, Cowan MJ, Danaei G, Lin JK, Paciorek CJ, et al. National, regional, and global trends in body-mass index since 1980: Systematic analysis of health examination surveys and epidemiological studies with 960 country-years and 9.1 million participants. Lancet. 2011;377:557-567. doi: 10.1016/S0140-6736(10)62037-5. 
[13] Mehmood Y, Al-Swailmi FK, Al-Enazi SA. Frequency of obesity and comorbidities in medical students. Pak J Med Sci. 2016;32(6):1528-1532. doi: https://doi.org/10.12669/pjms.326.10492

[14] Misra A, Jayawardena R, Anoop S. Obesity in South Asia: Phenotype, Morbidities, and Mitigation. Curr Obes Rep. 2019 Mar;8(1):43-52. doi: 10.1007/s13679-019-0328-0. PMID: 30729382.

[15] Al-Othaimeen AI, Al-Nozha M, Osman AK. Obesity: An emerging problem in Saudi Arabia. Analysis of data from the National Nutrition Survey. East Mediterr Health J. 2007;13:441-448.

[16] Al-Rethaiaa AS, Fahmy AE, Al-Shwaiyat NM. Obesity and eating habits among college students in Saudi Arabia: a cross sectional study. Nutr J. 2010;9(1):1.

[17] Peltzer K, Pengpid S, Samuels TA, Özcan NK, Mantilla C, Rahamefy OH, Wong ML, Gasparishvili A. Prevalence of Overweight/Obesity and Its Associated Factors among University Students from 22 Countries. Int. J. Environ. Res. Public Health 2014; 11: 7425-7441. doi:10.3390/ijerph110707425

[18] Sidor A, Rzymski P. Dietary Choices and Habits during COVID-19 Lockdown: Experience from Poland. Nutrients. 2020; 12: 1657.

[19] Pellegrini M, Ponzo V, Rosato R. Changes in Weight and Nutritional Habits in Adults with Obesity during the "Lockdown" Period Caused by the COVID-19 Virus Emergency. Nutrients. 2020; 12: 2016. doi:10.3390/nu12072016.

[20] Simonnet A, Chetboun M, Poissy J, Raverdy V, Noulette J, Duhamel A, Labreuche J, Mathieu D, Pattou F, Jourdain M. COVID-19 and Obesity study group. High Prevalence of Obesity in Severe Acute Respiratory Syndrome Coronavirus-2 (SARS-CoV-2) Requiring Invasive Mechanical Ventilation. Obesity (Silver Spring). 2020 Jul;28(7):11951199. doi: 10.1002/oby.22831. Epub 2020 Jun 10. Erratum in: Obesity (Silver Spring). 2020 Oct;28(10):1994. PMID: 32271993; PMCID: PMC7262326.. [CrossRef] [PubMed]

[21] Lee IM, Shiroma EJ, Lobelo F, Puska P, Blair SN, Katzmarzyk PT, Lancet Physical Activity Series Working Group. Effect of physical inactivity on major non-communicable diseases worldwide: an analysis of burden of disease and life expectancy. Lancet 2012;380:219-29. doi:10.1016/S0140-6736(12)61031-9

[22] Zhao M, Veeranki SP, Magnussen CG, Xi B. Recommended physical activity and all cause and cause specific mortality in US adults: prospective cohort study. BMJ 2020;370:m2031 http://dx.doi.org/10.1136/bmj.m2031 
[23] Aziz K, Afridi A, Arif A, Shahid G, et al. Association of Physical activity levels and BMI Among Doctor of Physical Therapy Students of a Private College from Karachi. JBUMDC 2019; 9(4):281-285.

[24] Huang Y, Zhao N. Generalized anxiety disorder, depressive symptoms and sleep quality during COVID-19 outbreak in China: A web-based cross-sectional survey. Psychiatry Res. 2020; 288: 112954. [CrossRef]

[25] Sønderskov KM, Dinesen PT, Santini ZI, Østergaard SD. The depressive state of Denmark during the COVID-19 pandemic. Acta Neuropsychiatr. 2020; 1-3. [CrossRef]

[26] Wang C, Pan R, Wan X, Tan Y, Xu L, Ho CS, Ho RC. Immediate psychological responses and associated factors during the initial stage of the 2019 Coronavirus Disease (COVID-19) epidemic among the general population in China. Int. J. Environ. Res. Public Health. 2020; 17: 1729. [CrossRef] [PubMed]

[27] Oosterhoff B, Palmer CA. Attitudes and Psychological Factors Associated With News Monitoring, Social Distancing, Disinfecting, and Hoarding Behaviors Among US Adolescents During the Coronavirus Disease 2019 Pandemic. JAMA Pediatr. 2020 Dec 1;174(12):1184-1190. doi: 10.1001/jamapediatrics.2020.1876. PMID: 32597925; PMCID: PMC7325067. 